\title{
An Investigation of Habituation in the Jellyfish Aurelia aurita
}

\author{
Mary C. Johnson and Karl L. Wuensch ${ }^{1}$ \\ Department of Psychology, East Carolina University, Greenville, North Carolina 27858-4353
}

Three experiments were conducted to examine the effectiveness of different forms of tactile stimulation, probe and stream, and interstimulus intervals (ISI) in producing habituation in the polypoid sessile stage of the jellyfish Aurelia aurita. Results from Experiment 1 showed that polyps significantly decreased their responsiveness to both forms of tactile stimulation with 30-s ISI across 60 trials. Response to a novel stimulus indicated that the response decrement had not been due to fatigue. When the ISI was lengthened to $6 \mathrm{~min}$ in Experiment 2, response to the probe form of tactile stimulation did not significantly decrease across 20 trials. Using an ISI of $1 \mathrm{~min}$ in Experiment 3 , response to the probe form of tactile stimulation decreased significantly across 40 trials. A significant increase in response to the original stimulus (dishabituation) following presentation of a novel stimulus indicated that response decrement was due to habituation or a habituation-like process rather than simple effector fatigue or sensory adaptation. 1994 Academic Press, Inc.

Habituation is considered by many to be the most basic, ubiquitious type of learning. Formally stated, it is a decrease in responsiveness as a result of repeated stimulation (Domjan \& Burkhard, 1986). Like sensitization, habituation is thought to involve neurophysiological changes and is thus different from response fatigue and sensory adaptation (Domjan \& Burkhard, 1986). This behavioral adaptation makes an organism more plastic and thus plays an essential role in the organism's survival and adaptation to its environmental niche. Habituation has been investigated quite thoroughly in the Hydra (Rushforth, 1965, 1967; Rushforth, Burnett, \& Maynard, 1963) and in the Pacific shore sea anenome, Anthopleura elangitissima (Logan, 1975; Logan \& Beck, 1978). From the studies done on the

\footnotetext{
1 This report is based on a thesis submitted by the first author in partial fulfillment of the requirements for the M.A. degree in psychology at East Carolina University. Address correspondence and reprint requests to $K$. L. Wuensch, Department of Psychology, East Carolina University, Greenville, NC 27858-4353. e-mail: pswuensc@ecuvm1.bitnet.
}

Hydra, Rushforth (1973) has summarized its response to mechanical agitation with regard to five of the nine parameters of habituation set forth by Thompson and Spencer (1966):

1. Repeated applications of the mechanical stimulus result in a decreased response, the decrease is approximately a negative exponential function of the number of stimulus presentations;

2 . If the stimulus is withheld, the original response recovers with time;

3. The shorter the interstimulus interval (ISI), the more rapid is habituation;

4. Increasing the strength of the stimulus produces a slower rate of habituation; the result would not be expected if the process were one of fatigue; and

5. The animals habituate faster on a second exposure to the initial habituation regime (p. 141).

Logan (1975) found that repeated presentation of a stream of fresh water resulted in habituation of the contractile response in the sea anenome, $A$. elangitissima. Several of the characteristics of habituation reported for more complex organisms (Hinde, 1970; Petrinovich, 1973; Thompson \& Spencer, 1966) were present. These include "response decrement with repeated stimulation, spontaneous recovery of responding with time, an increased asymptotic level of responding with longer stimulus duration, the retention of habituation, occasional dishabituation, and changes in response topography accompanying habituation" (Logan, 1975, p. 115). More recently Logan and Beck (1978) revealed that A. elangitissima exhibit long-term retention effects for up to 4 days following initial habituation.

Behavioral adaptation that is different from both sensory adaptation and muscular fatigue is now a well-accepted phenomenon among cnidarians (Logan, 1975; Rushforth, 1973), which lack cephalization and a centralized nervous system (Brusca \& Brusca, 1990). These studies, however, have been 
restricted to members of the class Anthozoa (Logan, 1975; Logan \& Beck, 1978) and Hydrozoa (Rushforth, 1965, 1967, 1973; Rushforth et al., 1963). The reasons for the present study were (a) to investigate the generalization of habituation across classes to include the class Scyphozoa, (b) to examine habituation using stimuli that reflect the organism's ecological niche, and (c) to test habituation in the polypoid stage, whose nervous organization consists of only a single conducting nerve net (Chia, Amerongen, \& Peteya, 1984), prior to the developmental changes that occur during strobilation. According to Schwab (1977) A. aurita polyps exhibit two types of behavior: local responses and coordinated activity, the latter requiring integrated responses in several body parts and assumed to be mediated by neuronal conduction. Two polyp behaviors which fall in the category of coordinated activity are feeding and the protective response (Schwab, 1977). If these coordinated behaviors are indeed neurally controlled, then one might expect to be able to demonstrate habituation and dishabituation in them. The feeding response requires a coordination between actions of the tentacle and the mouth, e.g., bending tentacle(s) toward the mouth or in the mouth (Schwab, 1977). The protective response involves symmetrical contraction of the column accompanied by the "simultaneous shortening and folding of the tentacles over the mouth" (Schwab, 1977, p. 237). It was these responses that were of interest and measured in the presently reported investigation. The specific goals of the research were to (a) evaluate the effectiveness/practicality of various stimuli for producing the contractile response, (b) determine whether $A$. aurita show a decrement in frequency of response following repeated stimulation, (c) if repeated stimulation is followed by response decrement, test whether the response can still be elicited by a novel stimulus, and (d) determine if the response to the original stimulus returns (dishabituation) after exposure to such a novel stimulus.

\section{GENERAL METHOD}

\section{Subjects}

Sixteen $A$. aurita polyps were obtained from two of the colonies, eight from each colony, maintained by Dr. Dorothy Spangenburg at the Medical College of Hampton Roads in Norfolk, Virginia. The size of these radially symmetrical polyps ranged from 2 to $3 \mathrm{~mm}$ in length. They were individually maintained at $12^{\circ} \mathrm{C}$ in iodine-free artificial seawater (iodine-free to prevent strobilation), also obtained from $\mathrm{Dr}$. Spangenburg. The artificial seawater was prepared using a recipe modified by Spangenburg (1965) and was run through an AG-1-X2 anion exchange column to remove iodide (Spangenburg, 1971). The seawater was prepared as follows (Spangenburg, 1965 , p. 304): Sodium chloride ( $23.47 \mathrm{~g} /$ liter $)$, magnesium chloride ( $4.98 \mathrm{~g} /$ liter), sodium sulfate (3.91 $\mathrm{g} /$ liter), calcium chloride (1.10 g/liter), potassium chloride $(0.664 \mathrm{~g} /$ liter $)$, sodium bicarbonate $(0.192$ $\mathrm{g} /$ liter), potassium bromide ( $0.096 \mathrm{~g} / \mathrm{liter})$, and boric acid $(0.026 \mathrm{~g} /$ liter $)$. Three days prior to testing the polyps were fed newly hatched brine shrimp, Artemia, and 1 day later they were individually housed in 500-ml Corning Pyrex glass bowls containing 100 $\mathrm{ml}$ of clean iodine-free artificial seawater. They were fasted during the experimental period so as not to interfere with testing. Prior to testing the water temperature was gradually adjusted to approximately $24^{\circ} \mathrm{C}$. Between testing periods a minimum rest interval of 28 days was used for each polyp.

\section{Materials}

Habituation training was performed in $500-\mathrm{ml}$ Corning Pyrex glass bowls containing $100 \mathrm{ml}$ of iodine-free artificial seawater. Bowls containing individual polyps were situated on a stable, flat black surface which reduced random movement of the water and improved visibility. Observations were made through a Bausch \& Lomb magnifying eyepiece ( $4 \times$ magnification). Illumination was provided by a $60-\mathrm{W}$ bulb, $37 \mathrm{~cm}$ above the bowl. ISI was regulated by an adjustable timer.

\section{Training Procedures}

Three different types of tactile stimulation were used: stream, probe, and shake. Stream was defined as $0.1 \mathrm{ml}$ of water squirted from a 1-ml Clay Adams pipetter with a disposable tip onto the polyp at the base of its tentacles. The tip of the pipet was held approximately $1 \mathrm{~mm}$ from the polyp. Probe was defined as gently touching the polyp at the base of its tentacles with a FISHERbrand Pasteur pipet. Shake was defined as manually lifting the bowl and briefly agitating it with a circular motion for about $2 \mathrm{~s}$. These three types of tactile stimulation were used as habituating and/or dishabituating stimuli.

\section{EXPERIMENT 1}

Reviewing the literature we found no studies pertaining to habituation in the A. aurita polyp. Pilot studies (Experiment 1) were thus performed to ex- 


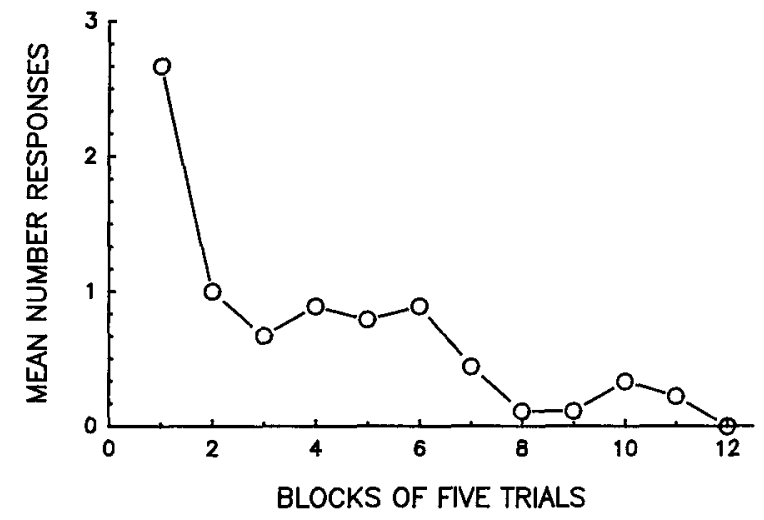

FIG. 1. Response decrement with a 30-s ISI using probe and stream as the testing stimuli.

plore and determine appropriate stimuli and values for ISI.

\section{Method}

Sixteen polyps were used. Eleven were tested with 30 -s ISI, four using the probe and seven using the stream. For the first of the 11 polyps the stimulus was presented for $4 \mathrm{~h}$, without a criterion set for discontinuing, and no novel stimulus was presented after the last trial. For the remaining polyps, stimulus presentation continued until the polyp failed to respond on 20 consecutive trials, and a novel stimulus was presented $30 \mathrm{~s}$ after its last trial. The novel stimulus was either the stream or the probe, whichever had not been previously presented. Five polyps were run with 60 -s ISI, one polyp using the probe, and four using the stream. Stimulus presentation continued until the polyp failed to respond on 20 consecutive trials. A novel stimulus, either the stream or the probe, whichever had not been used, was presented $60 \mathrm{~s}$ after the last trial.

\section{Results}

Among the 30-s ISI polyps two from among those that were given the stream as the trial stimulus were dropped because they were totally unresponsive. The number of responses per block of five consecutive trials (for the first 60 trials) was used as the dependent variable in a 12 by 2 , Block by Type of Stimulus profile analysis. Since there were too few data for a multivariate approach analysis, the univariate approach was used, with degrees of freedom adjusted to correct for violation of the sphericity assumption (Greenhouse \& Geisser, 1959). The only significant $(p<.05)$ effect was the block effect, which is illustrated in Fig. $1, F(3.2,22.2)=5.57$, $p=.005$. Profile contrasts indicated that respon- siveness decreased significantly from the first to the second block, $F(1,7)=17.29, p=.004$, and from the sixth to the seventh block, $F(1,7)=5.73, p$ $=.048$. The mean number of trials to criterion (the number of the trial upon which the last response was made prior to 20 consecutive nonresponses), which was not significantly affected by type of stimulus, $t(7)=0.20, p=.84$, was 33.0. All eight polyps responded to the novel stimulus, indicating that the response decrement had not been due to fatigue.

Two polyps from among those that were given the stream as the initial stimulus were dropped from the 60-s ISI because they were totally unresponsive. The three remaining polyps were too few for inferential statistics. The mean number of trials to criterion for these three was 45.3 .

\section{Discussion}

The reader should keep in mind the pilot nature of Experiment 1. It became obvious to the researchers after testing the first polyp that a criterion for discontinuing (other than after $4 \mathrm{~h}$ ) was needed, as that polyp had ceased responding well before 4 $h$ had passed. Thus, we set the 20 consecutive nonresponses criterion. After having tested polyps with the 30 -s ISI, the results made it obvious that a response decrement could be established with such an ISI. We then decided to try a 60-s ISI, aware that data from five polyps might not be enough to draw any strong conclusions. The increased mean trials to criterion at the 60-s ISI did suggest that habituation would be reduced at even longer ISIs. Since all of the nonresponsive polyps had been tested with stream stimulus, we decided that the probe stimulus was more effective.

\section{EXPERIMENT 2}

In Experiment 2 we made comparisons between 2- and 6-min ISI. The reasons for this redirection of focus were (a) the pilot work (Experiment 1) indicated a response decrement at 30-s ISI in less than $3 \mathrm{~min}$; (b) the work of Jennings (1905) on the sea anenome, Aiptasia annulata, did not show response decrement with an ISI longer than 5 min but did show a decrement at an ISI of less than $3 \mathrm{~min}$; and (c) to introduce a dishabituation test phase after having demonstrated that decrement to one stimulus did not eliminate responsiveness to a novel stimulus.

\section{Method}

Twelve polyps were tested with a 6-min ISI. The training stimulus was the probe. The stimulus was 


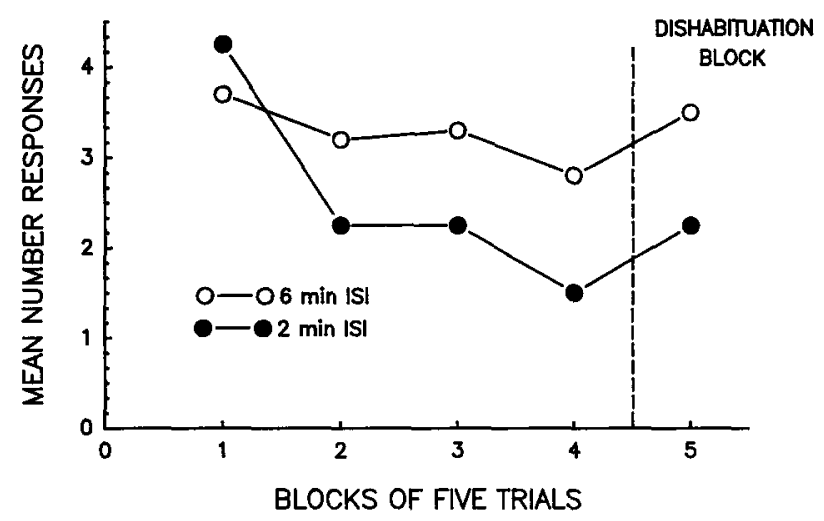

FIG. 2. Twenty habituation trials followed by five dishabituation trials. Probe was used as the testing stimulus in both the 6- and 2-min ISI. Stream or shake was used as the novel stimulus for the 6-min ISI and stream was used as the novel stimulus for the 2-min ISI.

presented 20 times or until the polyp failed to respond on 10 consecutive trials (none of the animals in Experiment 1 resumed responding after having failed to respond on 10 consecutive trials). Six minutes after the last training trial a novel stimulus, either the stream or shake, was presented. Six minutes later a final series of five dishabituation test trials with the original test stimulus and a 6-min ISI was presented. Four polyps were tested with a 2-min ISI, using the probe as the testing/training stimulus and the stream as the novel stimulus. The stimulus was discontinued after the polyp failed to respond on 10 consecutive trials. Two minutes after the last training trial a novel stimulus was presented and was followed 2 min later by a final series of five dishabituation test trials with the original test stimulus and a 2-min ISI.

\section{Results}

Two polyps were dropped from the 6-min ISI because they were totally unresponsive. A 5 by 2 , Block by Type of Novel Stimulus multivariate approach profile analysis, using Pillai's trace for multivariate tests of significance, with the number of responses per block of five consecutive trials serving as the dependent variable, revealed no significant effects of the block, $F(4,5)=0.50, p=.74$ or the Block by Type of Novel Stimulus, $F(4,5)=3.49$, $p=.10$, or type of novel stimulus, $F(1,8)=1.72$, $p=.23$. As illustrated in Fig. 2, with a 6-min ISI there appears to be no response decrement with repeated stimulation. Only one polyp met the 10-trial criterion, making its last response on trial 3.

Data from all four of the polyps tested with a 2min ISI were used in a second analysis. Although the means suggest that habituation took place, due to low power (low $\mathrm{N}$ ), the only significant effect in a one-way univariate approach profile analysis was the contrast between the first block and the second, $F(1,3)=12.00, p=.0405$ (see Fig. 2). The omnibus effect of block was also not significant, $F(1.9,5.6)$ $=2.52, p=.17$. No polyp reached the 10 -trial criterion.

\section{Discussion}

It should be noted that the polyps used in Experiment 2 were the same as those used in Experiment 1 (and to be used again in Experiment 3). We do not believe that savings was a problem since no polyp was tested with less than 28 days rest between its participation in one experiment and its participation in another. We think it unlikely that any effects of habituation in these animals would persist across such a time period. The animals which were nonresponsive in Experiment 1 (using the stream stimulus) were all responsive in Experiment 2. Their nonresponse in Experiment 1 must have been due to some transient state or our problems using the stream stimulus.

As in Experiment 1, our unequal sample sizes resulted from a decision made during the experiment rather than a priori. After testing polyps with the 6-min ISI it was obvious that no substantial response decrement was taking place. We wanted to see if reducing the ISI to $2 \mathrm{~min}$ would restore the response decrement on the remaining four polyps.

\section{EXPERIMENT 3}

Results of the first two experiments suggested that response decrement can be reliably obtained with a short ISI ( 1 min or less) but not with a long ISI $(6 \mathrm{~min})$. We returned to a short ISI to test for habituation and dishabituation.

\section{Method}

Sixteen polyps were tested with the probe stimulus using an ISI of $1 \mathrm{~min}$. The stimulus was presented 40 times or until the polyp failed to respond on 10 consecutive trials. One minute after the last training trial the shake was delivered as the novel stimulus, and 1 min later five dishabituation trials with the probe and 1-min ISI were presented.

\section{Results}

One polyp was dropped because it was totally unresponsive. Using the number of responses per block 


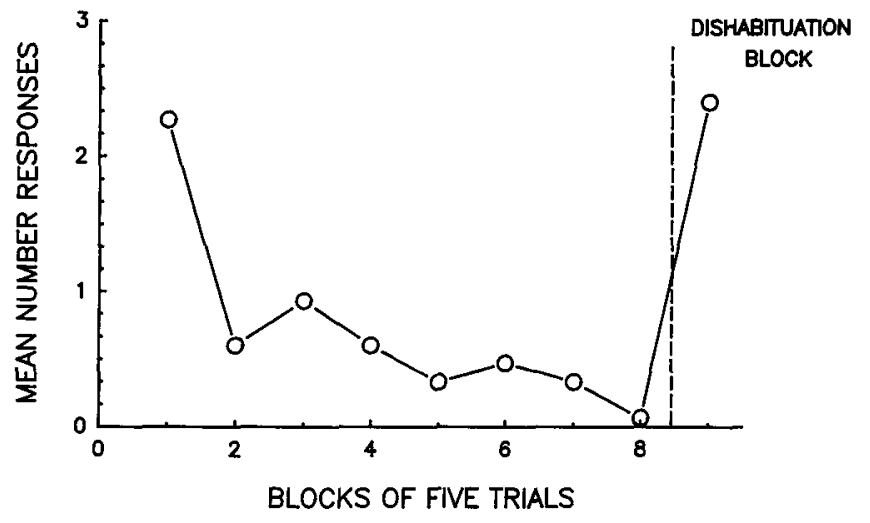

FIG. 3. Habituation and dishabituation with a 1-min ISI using probe as the testing stimulus and shake as the novel stimulus.

of five consecutive trials as the dependent variable, a multivariate approach profile analysis revealed a significant effect of block, $F(8,7)=15.44, p<$ .001. Profile contrasts indicated that responsiveness significantly decreased from the first to the second blocks, $F(1,14)=25.00, p<.001$ and significantly increased from the last training block to the dishabituation block, $F(1,14)=85.75, p<.001$ (see Fig. 3 ). The recovery of the response following presentation of the novel stimulus (dishabituation) indicates that the response decrement is due to habituation or a habituation-like process rather than simple effector fatigue or sensory adaptation. The mean trials to criterion was 15.2.

\section{GENERAL DISCUSSION}

The present data are congruent with habituation studies of Logan (1975) and Rushforth (Rushforth, 1965, 1973; Rushforth et al., 1963). Both Logan and Rushforth have shown a decrement in response following repeated presentations of a stimulus in the sea anenome $A$. elangitissima and the two species of hydra, Hydra pirardi and Hydra viridis, respectively. It should be noted that the contractile response we observed may well not be an "all or nothing" response; that is, responses may have differed from one another in intensity. Not having the equipment to measure intensity of contraction in such a small organism, we resorted to classifying responses as simply present or absent. The response decrement to tactile stimulation obtained in the present study and in other cnidarian behavior studies makes it possible to generalize the process of habituation across phyla to include the jellyfish $A$. aurita polyp, and is further support for adaptability among animals lacking cephalization and a centralized nervous system.

With regard to the nine characteristics of habituation set forth by Thompson and Spencer (1966), our results demonstrated three of those characteristics. For short ISIs the results clearly showed decreased probability of response with repeated stimulation. This is consistent with Thompson and Spencer's characteristic that repeated presentations of a stimulus led to a decrease in response. Response to a novel stimulus indicated that the response decrement had not been due to fatigue. When the ISI was lengthened to $6 \mathrm{~min}$, repeated presentation did not result in a significant decrease in response to tactile stimulation. This goes along Thompson and Spencer's characteristic that habituation is more rapid and/or pronounced when the rate of the stimulus increases. The results of the dishabituation training in Experiment 3 correspond to Thompson and Spencer's characteristic that the habituated response recovers when a novel stimulus is presented. This indicates that the earlier response decrement was due to neurophysiological changes rather than response fatigue and suggests that the response studied represents coordinated activity and as suggested by Schwab (1977) is controlled neurally.

These results open the door to further investigation of habituation in the jellyfish polyp A. aurita, namely additional tests of the characteristics set forth by Thompson and Spencer. The next logical step would be to study the retention of habituation, spontaneous recovery, and potentiation of habituation.

\section{REFERENCES}

Brusca, R. C., \& Brusca, G. J. (1990). Invertebrates. Sunderland, MA: Sinauer Associates, Inc.

Chia, F. S., Amerongen, H. M., \& Peteya, D. J. (1984). Ultrastructure of the neuromuscular system of the polyp of $A u$ relia aurita. Journal of Morphology, 180, 69-79.

Domjan, M., \& Burkhard, B. (1986). The principles of learning and behavior (2nd ed.). Belmont, CA: Brooks/Cole.

Greenhouse, S. W., \& Geisser, S. (1959). On methods in the analysis of profile data. Psychometrika, 24, 95-112.

Hinde, R. A. (1970). Behavioral habituation. In G. Horn \& R. A. Hinde (Eds.), Short-term changes in neural activity and behaviour (pp. 7-37). Cambridge: Cambridge Univ. Press.

Jennings, H. S. (1905). Modifiability in behavior. I. Behavior of sea anenomes. Journal of Experimental Zoology, 2, 447-473.

Logan, C. A. (1975). Topographic changes in responding during habituation to waterstream stimulation in sea anenomes (Anthopleura elangitissima). Journal of Comparative and Physiological Psychology, 89, 105-117.

Logan, C. A., \& Beck, H. P. (1978). Long-term retention of habituation in the sea anenome (Anthopleura elangitissima). 
Journal of Comparative and Physiological Psychology, 92, 928-936.

Petrinovich, L. (1973). A species-meaningful analysis of habituation. In H. V. S. Peeke \& M. J. Herz (Eds.), Habituation, Vol. 1. Behavioral studies (pp. 141-162). New York: Academic Press.

Rushforth, N. B. (1965). Behavioral studies of the coelenterate, Hydra pirardi Brien. Animal Behavior Supplement, 13,(Suppl. 1), 30-42.

Rushforth, N. B. (1967). Chemical and physical factors affecting behavior in Hydra: Interactions among factors affecting behavior in Hydra. In W. C. Corning \& S. C. Ratner (Eds.), Chemistry of learning (pp. 369-390). New York: Plenum Press.

Rushforth, N. B. (1973). Behavioral modification in coelenterates. In W. C. Corning, J. A. Dyal, \& A. O. D. Willows (Eds.),
Invertebrate learning: Vol. 1. Protozoans through annelids (pp. 123-169). New York: Plenum Press.

Rushforth, N. B., Burnett, A. L., \& Maynard, R. (1963). Behavior in Hydra: Contraction response of Hydra pirardi to mechanical and light stimuli. Science, 139, 760-761.

Schwab, W. E. (1977). The ontogeny of swimming behavior in the scyphozoan, Aurelia aurita. I. Electrophysiological analysis. Biological Bulletin, 152, 233-250.

Spangenburg, D. B. (1965). Cultivation of the life stages of $A u$ relia aurita under controlled conditions. Journal of Experimental Zoology, 159, 233-250.

Spangenburg, D. B. (1971). Thyroxine induced metamorphosis in Aurelia. Journal of Experimental Zoology, 178, 183-194.

Thompson, R. F., \& Spencer W. A. (1966). Habituation: A model phenomenon for the study of neuronal substrates of behavior. Psychological Review, 73, 16-43. 